two days in hospital was $\$ 3500$. Not bad, commented someone else, considering that hospitals now charge $\$ 5000$ for a routine delivery. Moreover, the obstetrician's fee is extra, and quite high indeed, because it has to include a $\$ 40000$ a year malpractice premium. It goes to show that the problems are complex and the solutions hard to come by.

So ended this particular symposium. The one described by Plato, however, was not about sickness but about love. Socrates was there, as were Aristoph- anes and Alcibiades, and they drank well into the night, achieving some degree of "divine madness," for it was before the automobile and the breathalyser.

But later in the night, on the car radio, there was tenor John McCormak singing from the Rubaiyat:

Myself when young did eagerly frequent

Doctor and saint, and heart great argument

About it and about: but evermore

Came out by the same door as in I went.

An appropriate finale for the evening.

\title{
Housing and Health
}

\section{Health and homelessness}

\section{Stella Lowry}

Homelessness has been the backdrop of English life for many years - with harsh vagrancy laws under the Tudors, the Hard Times of the Victorians (Engels found no fewer than 50000 homeless in London alone' ${ }^{1}$, and the cardboard cities outside the National Theatre and other landmarks today. But how big is the contemporary problem?

A recent survey found that 751 people were sleeping rough on the streets in 17 of London's boroughs on one night, and that did not include people sleeping in derelict buildings, parks, or car parks. ${ }^{2}$ In 1988 local authorities in England accepted that people in no fewer than 117550 households were homeless (up nearly 5\% on the previous year)-representing, according to the housing charity Shelter, about 337000 people, though their own estimates are nearer 500000 . Here I discuss the health problems faced by homeless people and explore ways of providing care.

\section{Born homeless}

The number of homes available for rent in Britain has decreased by a million in the past 25 years. Legislation giving council tenants the right to buy their homes, often at heavily subsidised prices, has creamed off some of the better public housing to private ownership, and public sector building has not kept pace with the loss. In 1986-7 some 1700 new dwellings were built by the London boroughs, but 13500 houses were expected to be sold to tenants.

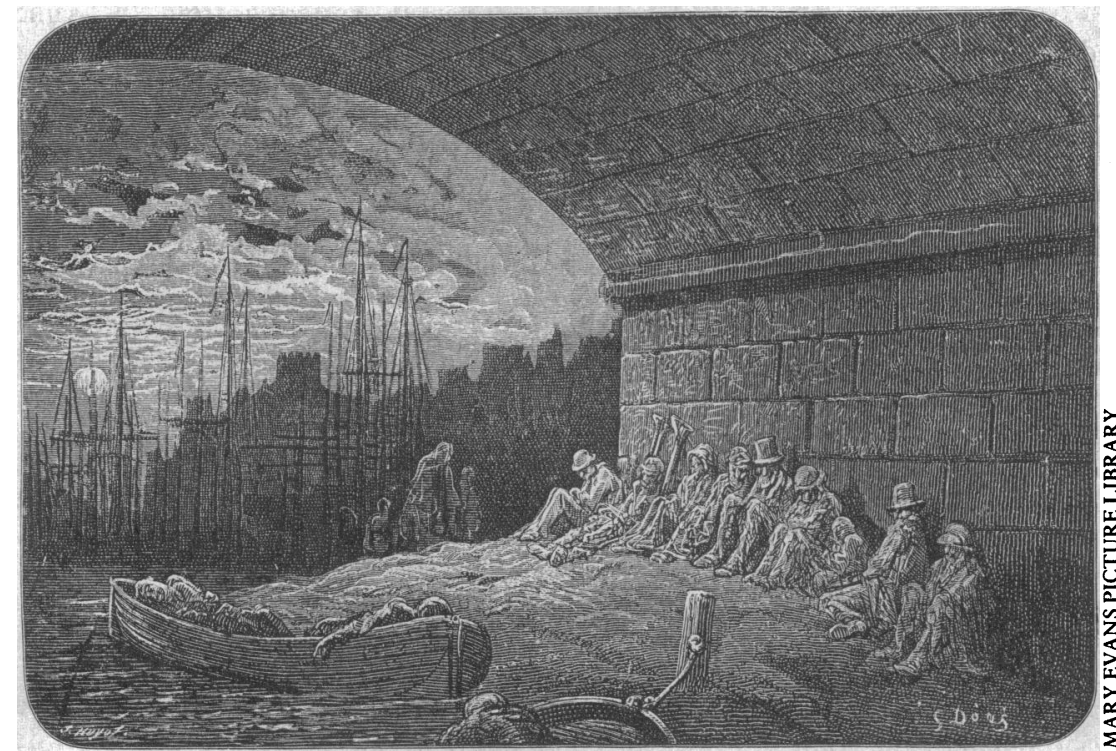

Down and out in 1870
Families with children have a right to housing under part 3 of the 1985 housing act. But because there are so few public sector houses available homeless families are often placed temporarily in bed and breakfast hotels. Not unusually such "temporary" arrangements may last for several years.

Living in a bed and breakfast hotel is not an extended luxury holiday. It means keeping all of your belongings in one room, living out of suitcases, and having no privacy. Children are born and brought up in one room, where they live with the rest of their family. There is no safe place to play. Washing and cooking facilities are shared with other families, and there may be nowhere to store food. If the cooking facilities are several floors away residents have to choose between eating takeaways, having cold meals, or carrying saucepans of hot food up several flights of stairs, often with children in tow.

The adverse effects of these conditions on health have been well documented. ${ }^{3}$ Homeless women are twice as likely to have problems and three times as likely to need admission to hospital during pregnancy as other women. A quarter of babies born to mothers living in bed and breakfast accommodation are of low birth weight, compared with a national average of less than 1 in 10 . The children are more likely to miss out on their immunisations, while poor sanitation and overcrowding encourage the spread of infections and diarrhoeal illnesses. Good nutrition is almost impossible because of the poor facilities for storing and cooking food. Accidents are common among the children, and their parents often suffer from depression.

\section{Sleeping rough}

No one knows how many people sleep on the streets in Britain each night, but it is probably several thousand. Some people choose to live rough, but many drift on to the streets because they cannot cope with personal and financial problems. An increasing number have been discharged from disbanded long stay mental hospitals. ${ }^{4}$ High interest rates mean that some people are homeless because they cannot meet their mortgage repayments. In 1987 building societies repossessed 22930 homes, and by June 1989 over 45000 buyers were more than six months in arrears.

Once on the streets it is hard to keep healthy. The shelter, warmth, and privacy often taken for granted do not exist; good food may be hard to find or expensive; it is almost impossible to keep clean; "minor" illnesses are hard to cure.

Dr Malcolm Weller, a consultant psychiatrist in London, conducted a survey of the homeless people attending the Crisis at Christmas venue in 1986. About 


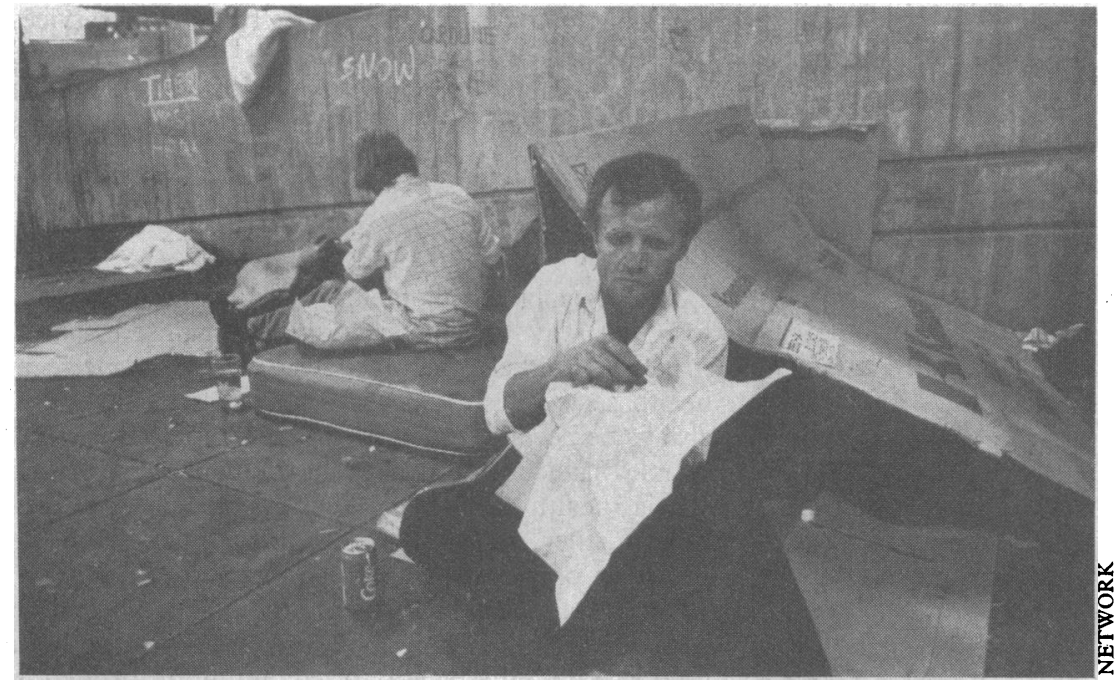

1989-What has changed? mothers and children in bed and breakfast hotels is particularly important. These families are told that the arrangements are temporary, so many do not even try to register with a general practitioner. Many who do try give up after a few rebuffs from doctors unwilling to take on such "problem families," and few realise that the local family practitioner committee will find them a doctor.

One solution, by Dr Richard Stone of the Bayswater Hotel Homeless Project, ${ }^{9}$ is to cater specifically for homeless families but to ensure that they have all the benefits of registration with a local doctor. The project pays local general practitioners for sessions at a special surgery. When a family attends it is temporarily registered with the doctor on duty, and after three months permanent registration is arranged.

The Health Visitors Association and the General Medical Services Committee of the BMA have suggested ways of improving primary care for homeless people, including better communication among health workers and using patient held records to improve the continuity of care. ${ }^{10}$

Nevertheless, the changes in the new contract for general practitioners may make it more difficult to provide health care for homeless people-who are not strictly resident in a district; So will their needs be budgeted for? The numerous health and social problems of homeless people make them an unattractive proposition to general practitioners aiming at large lists and a high uptake of immunisation and cervical smear tests.

"What is it like to suffer even from simple diarrhoea when there are no public toilets?... What is it like to recover from an amputation while struggling with alcoholism and diabetes when there isn't even a place to store one's insulin, much less a source of a diabetic diet?’’

Students and doctors at the mobile clinics run by the Whytham Hall Centre in Maida Vale often see infestations and minor skin conditions complicated by secondary infections. Their residential beds are often used by homeless people who need regular meals, clean conditions, and encouragement to comply with the treatment for pulmonary tuberculosis. ${ }^{6}$ But otherwise, understandably, it can be difficult to find a general practitioner willing to take on homeless people; they are often hard to motivate about taking medicines and keeping appointments, and their psychiatric problems reduce cooperation even further. They may well leave the practice area before their old notes have been traced. A dirty, unkempt person in the waiting room may upset other patients and the staff.

Even so, all the evidence is that if facilities are provided homeless people will use them. The Great Chapel Street clinic in London's Soho is one of several walk in centres providing general practitioner services to homeless people. ${ }^{7}$ There is no appointment system, so patients come when they like and are usually well motivated to comply with treatment. And many come back for follow up.

\section{Primary care for the homeless}

Schemes such as that at Great Chapel Street do work, but should we be concentrating on special schemes to provide primary care for homeless people? Given that medicine is slowly losing its emphasis on cure and concentrating on prevention, there is a danger that the homeless - who are perhaps most in need of preventive medicine-may miss out because there is no continuity of primary care. Thus the Policy Studies Institute has recently concluded that special services for homeless people may lead to their further isolation, while the range of care offered is less than could be provided by normal services. ${ }^{8}$

Providing a comprehensive health service to

\section{Hospital care}

Even if primary care could be arranged for homeless people the difficulties of access to inpatient services would remain. Hospitals often hide behind catchment area restrictions, and homeless people can end up as no one's responsibility.

Discharging homeless people from hospital is also difficult. Given the increasing pressure to have a rapid turnover of patients, hospitals are increasingly using day case surgery and early discharge to the primary health care team. Yet homeless people often have nowhere to go; sometimes they are discharged to hostels, but these rarely have any medical or nursing supervision.

The London Medical Campaign Project was founded in 1986 after publicity about several homeless patients whose health deteriorated and who died soon after they were discharged from hospital. ${ }^{11}$ Trying to coordinate health services for London's homeless, this project has worked with agencies such as the Royal College of General Practitioners and the Royal College of Nursing to educate professionals about their special needs. The campaign runs solely on charitable funding, and it has enough money only to fund one full time

\section{Families in bed and breakfast accommodation speak out}

"There's only one cooker between about 130 people ... and if you do start cooking and then go back to your room then your dinner either gets burnt or stolen."

"My daughter has been scalded and other children have had electric shocks. In your own home you can be careful, have gates across doorways etc, but in a hotel you've got to put up with other people being careless."

". . . it is very difficult to do my homework. ... I try to do my work on the bed but it's difficult as it sinks down in the middle." 


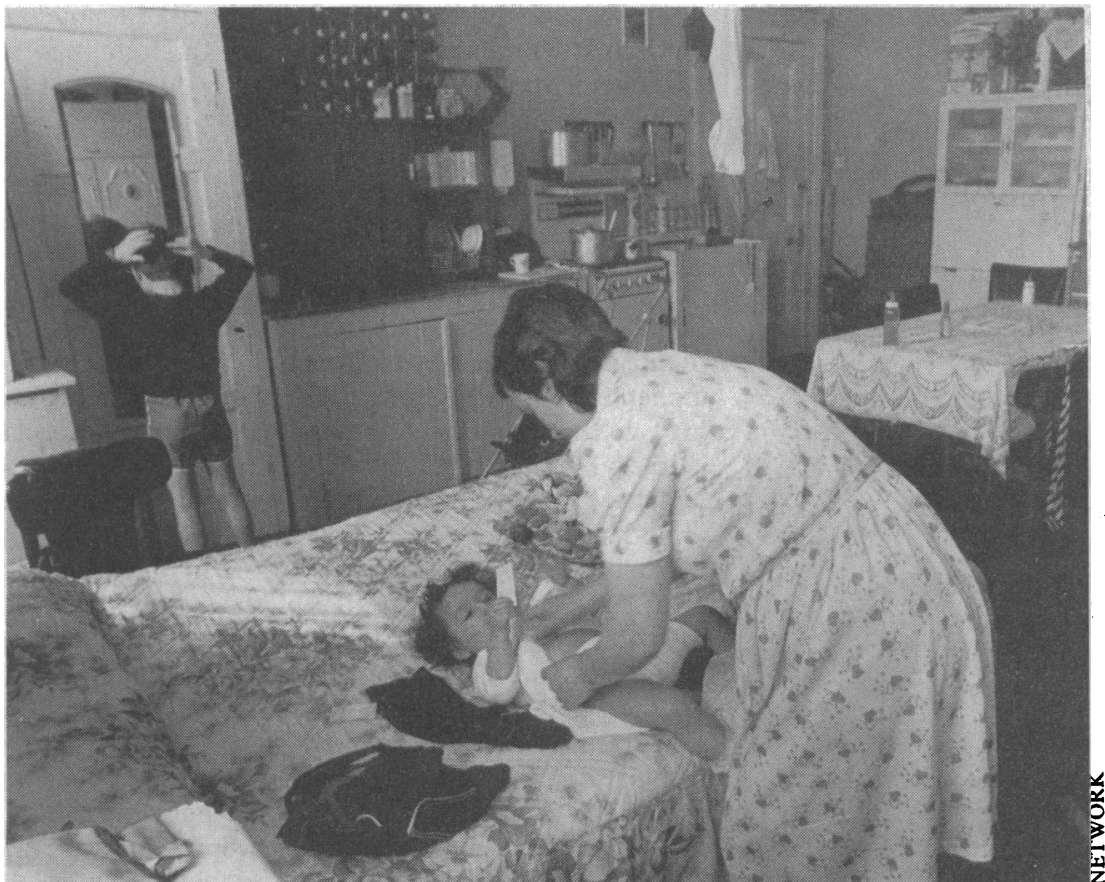

Living in a bed and breakfast

hotel is not an extended holiday

worker for the next three years. What's more, the workers find that they have to spend as much time on chasing funds as on working with the homeless.

\section{Conclusions}

Homelessness is bad for health. The consequences of life on the streets are all too obvious, but hostel dwellers are often little better off. Living in bed and breakfast accommodation is also damaging to health, yet some of our most vulnerable groupsyoung children and single mothers - are increasingly being placed in these conditions for months at a time.

There are two main ways of providing health care for homeless people, who need health care as much as anyone else, and often more. Firstly, existing services can be adapted to make them less intimidating and more accessible; secondly, special facilities can be provided. Either of these approaches can be successful when run by an enthusiastic team.

\section{Comment}

A few people are homeless because they choose to live that way. Their rejection of organised society makes it unlikely that they will accept mainstream health services, so that some specialist facilities will always be needed, especially in large cities. But many people have not chosen to be homeless. Providing special health services for these people marginalises them further, and it also hides the problem from the providers of mainstream services.

The ideal solution to their problems is an end to homelessness. But how likely is this, given the high interest rates, the paucity of community care for the mentally ill, and the shortage of public sector housing?

Doctors have a duty to speak out about the medical implications of the continuing problem of homelessness-something that no civilised society should accept.

1 Engels F. Condition of the working class in England in 1844. London: George Allen and Unwin, 1892.

2 Canter D, Drake M, Littler T, Moore J, Stockley D, Ball J. The faces of homelessness in London. Interim report to the Salvation Army. Guildford: Department of Psychology, University of Surrey, 1989.

3 Conway J, ed. Prescription for poor health. The crisis for homeless families. London: London Food Commission, Maternity Alliance, SHAC, Shelter, 1988.

4 Marshall $M$. Collected and neglected: are Oxford hostels for the homeless filling up with disabled psychiatric patients? Br Med $\mathcal{F} 1989 ; 299: 706-9$.

5 Hilfiker D. Are we comfortable with homelessness? YAMA 1989;262:1375-6. Ramsden SS, Baur S, El Kabir DJ. Tuberculosis among the central London single homeless. $f$ R Coll Physicians Lond 1988;22:16-7.

7 El Kabir DJ. Great Chapel Street Medical Centre. Br Med $\mathcal{F}$ 1982;284:480-1.

8 Williams S, Allen I. Health care for single homeless people. London: Policy Studies Institute, 1989.

9 Bayswater Hotel Homelessness Project. Speaking for ourselves. Families in Bayswater BE B. London: Bayswater Hotel Homelessness Project, 1987.

10 Health Visitors' Association and General Medical Services Committee. Homeless families and their health. London: British Medical Association, 1989.

11 Tyler A. Hospitals spurn homeless. Time Out 1985; 5 Dec:12-5.

\section{MATERIA PARAMEDICA}

\section{Facial palsy in representational art: ancient and modern}

I acquired an indolent non-suppurative gingivitis when in my late $60 \mathrm{~s}$. The consultant, suspecting something odd, arranged for tests, and a diagnosis of infectious mononucleosis was made-a most unusual, possibly unique, primary presentation at an unusual age. The kissing disease? "I should be so lucky!" as they say in the environs of Stanmore, north London. About two weeks later while driving to King's College Hospital, I noticed a curious sensation in the left side of my face. A glance in the windscreen mirror showed a left facial palsy.

My mind went back to a visit to the British Museum some 25 years previously. There I had seen and sketched a vividly represented facial palsy in a Moche pot (fig 1). The Moche culture of Peru lasted from $400 \mathrm{BC}$ until AD 760. The artist potters of that civilisation showed a strong tendency to represent distortions and grotesques due to illness and to deformities resulting from punishment. I make no apology for featuring this Moche pot, although it has been illustrated several times elsewhere, because I believe this to be the first time it has appeared in an English language medical journal. The British public first saw it, soon after discovery, in the Illustrated London News of 4 December 1909 (p 806).

Facial palsy has been shown in ancient native cultures elsewhere..$^{1-3}$ Many of these representations are crude and capable of other interpretations. None, in my opinion, equals the vivid veracity of this one. ${ }^{\star}$

Taking a leap to modern times, we have the self portrait (fig 2 ) of the Franco-Russian artist, Marc Chagall (d 1985). ${ }^{+}$This sketch shows a left sided palsy, but my guess is that it was right sided. - BERNARD J FREEDMAN

^The pot is in the Museum of Mankind and may now be seen only by prior arrangement. Telephone or write to: The Curator, Ethnographic Department, Museum of Mankind, 6 Burlington Gardens, London W1X 2EX. Tel 01437 2224; re Exhibit 1909. 12-18.25 British Museum.
Space for exhibiting these pots is not available, and items of medical or other subspecialty interests are unavailable for casual discovery. There are no subspecialty catalogues. Many objects are in storerooms with no means whereby members of the public with special interests can learn of their existence.

1 van Wagoner RS, Chun TH. Facial paralysis carved in Alaskan native masks. Alaska Medicine 1974;16:123-5.

2 Kindler W. Die Fazialislähmungen in der darstellenden Kunst seit mehr als 4 Jahrtausenden. Z Laryng Rhinol Otol 1970;49:1-5.

3 Steiner CB, El-Mallakh RS. Neurology 1988;38:822-3.

4 Chagall M. My life. London: Peter Owen, 1989.

Bernard Freedman died on 17 December 1989.
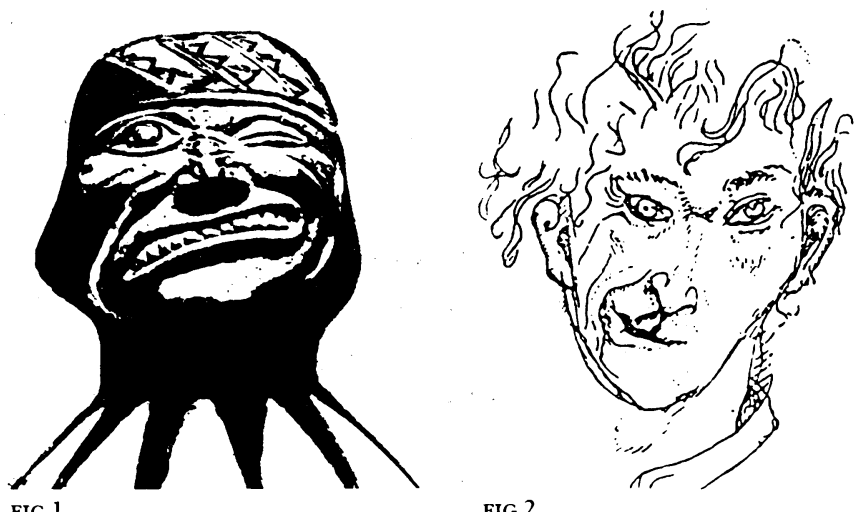

FIG 2 